\title{
SUBJETIVIDADES SOBRE LA CAUSALIDAD DE DIABETES MELLITUS ENTRE SEIS TSELTALES DE la CABeCERA Municipal de Tenejapa, Chiapas
}

\author{
Subjectivity about Causality of Diabetes Mellitus between Six Tseltals \\ from Main Town Tenejapa, Chiapas
}

\author{
Jaime Tomás Page-Pliego
}

Resumen: En este trabajo se abordan las subjetividades de seis tseltales de la cabecera municipal de Tenejapa con diabetes sobre las causas de su "azúcar". A través de sus narrativas, se desentraña lo que consideran causas directas y desencadenantes que, además, coadyuvan al agravamiento del padecimiento. Se da cuenta de la clara tendencia de la población del municipio a atribuir la causa a factores de orden natural-biológico, sin soslayar que en menor medida también se debe el daño producido por terceros, ak'chamel (mal echado), así como a factores de orden emocional.

Palabras clave: diabetes, subjetividad, causas directas, causas desencadenantes, tseltales.

Abstract: This paper is about the subjectivity of six Tseltals from the main town of Tenejapa, Chiapas, about what they consider the causes of their "sugar". Through their stories we figure out what they consider direct, triggering and persisting causes of their illness. We address the tendency in this population to enunciate natural factors over supernatural, without discarding the fact that we can still find those who deposit the cause in the damage produced by third persons through ak'chamel (emitted disease). The paper also considers the importance that is attributed to emotions as triggering and aggravating factors.

Keywords: diabetes, subjectivity, direct causes, triggering causes, Tseltales.

Jaime Tomás Page Pliego, doctor en Antropología Social por la Facultad de Filosofía y Letras de la Universidad Nacional Autónoma de México. Investigador en el Centro de Investigaciones Multidisciplinarias sobre Chiapas y la Frontera Sur de la Universidad Nacional Autónoma de México. Temas de especialización: etnomedicina, enfermedades del rezago y emergentes, sistemas y estrategias de salud. Correo electrónico: jaimepagepliego@gmail.com.
Enviado a dictamen: 22 de septiembre de 2014. Aprobación: 27 de marzo de 2015.

Revisiones: 2 . 


\section{Introducción}

E ste trabajo es parte de los resultados preliminares de la investigación "Representaciones sociales y estrategias de atención en torno a diabetes mellitus en población de la periferia de San Cristóbal de Las Casas y cabeceras municipales de Chamula y Tenejapa, Chiapas". Se analizan las subjetividades sobre lo que seis tseltales de la cabecera municipal de Tenejapa consideraron como causas de su "azúcar". Se tomaron en cuenta casos representativos y se realizaron entrevistas y seguimiento de trayectorias.

En 2010, el INEGI estimó en Tenejapa —municipio ubicado en el centro del estado de Chiapas, en la región V Altos Tsotsil-Tseltal - un total de 40208 habitantes, el 90\% tseltales ${ }^{1}$ y el resto mestizos, de los que 1998 (4.96\%) habitaban en la cabecera municipal (SEDESOL, 2012; INEGI, 2010). El municipio está considerado como de muy alta marginación, con 1.18 en una escala de 0 a 100 (CONAPO, 2010).

En las entrevistas sobre la diabetes mellitus, padecimiento al que llaman comúnmente "azúcar", resultó frecuente que la consideraran como una enfermedad nueva ya que antes de 1970 les era desconocida. En un caso particular, el señor Rafael (nombreficticio) afirmóque "[...] el azúcarprácticamente llegó por ahí de principios de los setenta junto con la carretera, y las tortillerías de Maseca vinieron a empeorar las cosas".

Como se puede observar en el cuadro 1, en 2008, la diabetes mellitus fue la sexta causa de muerte en el municipio, con una tasa de 10.18 por 100000 habitantes. En 2009 ocupó el segundo lugar, con una tasa de 27.65, y a partir de 2010, el primero, con una tasa de 44.7. Cabe destacar que el incremento en los decesos por diabetes mellitus entre 2008 y 2010 fue del $350 \%$.

\section{Metodología}

A finales de 2010 se aplicó una encuesta en el centro de la cabecera municipal de Tenejapa destinada a detectar enfermos crónicos. En el 30\% de los hogares se encontró al menos un diabético de tipo 1 o de tipo 2.
Al visitar los hogares en los que se detectaron personas diabéticas, en algunos fue posible entrevistar al afectado y simultáneamente descubrir a otros diabéticos no detectados en la encuesta, esto debido a que personas que conformaban las redes de los entrevistados espontáneamente se acercaron con objeto de participar en el proyecto. Un factor que coadyuvó a dicho interés fue la realización de glucometrías.

De los dieciséis diabéticos entrevistados, seleccionamos a ocho con vivencias más complejas con objeto de realizar el seguimiento de su trayectoria de 2011 a 2013. Para este trabajo fueron seleccionados seis casos (ver cuadro 2), representativos de los dieciséis sujetos. El consentimiento informado quedó registrado en las grabaciones que se realizaron, pero los nombres de los participantes considerados para este trabajo son ficticios. El análisis de información tuvo como base el contenido de dieciséis narrativas y trayectorias de diabéticos y sus familiares. Todos los datos recabados sobre los enfermos se realizaron estando vivos éstos.

\section{Marco referencial}

El estudio del padecimiento visto desde la triada padecimiento-enfermedad-dimensión macrosocial del proceso salud-enfermedad-atención (Kleinman, 1988; Good, 1994; Menéndez, 1994) ha sido abordado desde las esferas de la subjetividad y la transubjetividad (Jodelet, 2007: 51-52), estaúltima para dar cuenta de aspectos de la dimensión macrosocial del proceso salud-enfermedadatención, elementos que se encuentran presentes en las formas en que los tseltales que nos ocupan conciben y viven los procesos de salud-enfermedad-atención. Ellos otorgan coherencia a los conceptos y a las causas, así como a las estrategias que llevan a cabo en torno a la salud y la enfermedad.

En el contexto señalado, con Jodelet (2007: 5152) consideramos que la "esfera de la subjetividad" —desde donde se aborda el padecimiento- refiere a la apropiación/encarnación y elaboración de los procesos de experiencia del individuo a partir de procesos cognitivos, emocionales y prácticos, por medio de los cuales se configuran, transforman y 
cambian las representaciones de todo orden que circulan en el entorno de los sujetos. A través de esta esfera nos hemos acercado a lo que los sujetos consideran como causas directas y desencadenantes de su "azúcar".

La esfera de la "transubjetividad" influye e incluso es determinante en la configuración de la "esfera de la subjetividad" y sus dinámicas, ya que sus "elementos atraviesan tanto el nivel subjetivo como el intersubjetivo: [...] remite a todo lo que es común para los miembros de un mismo colectivo" (Jodelet, 2007:54).

En este punto, desde la transubjetividad, es importante recurrir a la noción de "horizonte", que refiere a los distintos ámbitos desde donde puede situarse un objeto:

La noción de horizonte en la que se encuentra encastrado el objeto permite superar el carácter unilineal de la noción de perspectiva. Porque el modo de enfocar los objetos y los acontecimientos que pueblan nuestro mundo cotidiano apela a sistemas de representaciones trans-subjetivas que modelan y matizan nuestras percepciones (Jodelet, 2007: 55).

\section{Vivir sufriendo de azúcar}

Los tseltales sujetos de estudio contemplados en este trabajo se desempeñan en un horizonte amplio que indistinta, alternada o simultáneamente permite concebir y vivir la salud, la enfermedad y las opciones de atención desde un abanico múltiple, en uno de cuyos extremos encontramos el ak'chamel (mal o enfermedad echada). ${ }^{2}$ Avanzando hacia la racionalidad biomédica, que constituye el otro extremo, nos encontramos con el susto, ${ }^{3}$ la envidia, ${ }^{4}$ los excesos dietéticos, el abuso de refrescos y cerveza, y que el "azúcar" viene de la sangre. Esta estructura no es inamovible, sino que se transfigura ${ }^{5}$ constantemente ante el impacto de diferentes agentes globales, como el proselitismo religioso, los merolicos, ${ }^{6}$ las acciones de venta de empresas de productos "herbolarios" y de "nutrición", como Omnilife y Herbalife, publicidad farmacéutica en los medios, etcétera.
¿Cómo nos explicamos la posibilidad de tal abanico? Para ello nos remitimos a la coexistencia de elementos religiosos en los que se entremezclan, por un lado, aspectos de la costumbre con elementos cristianos y, por otro lado, elementos de orden natural, cuyo rango va de aspectos como frío-calor, hasta de orden biomédico, inmersos en el continuum de una racionalidad que no cuestiona lógicas opuestas.

Así vemos que, para la conservación de la salud, los tenejapanecos requieren de conformar, a nivel individual y familiar, conductas que coadyuven a armonizar lo espiritual, mediante el mandato primordial de adorar y nutrir a las deidades (Page, 2005), con los aspectos de orden natural que se concretan en procesos materiales, tangibles o sensibles: frío o calor, sus puntos intermedios y sus extremos. Este plano ha incorporado, bajo su propia racionalidad, los procesos infecciosos y las condiciones genéticas o congénitas; asimismo, ha dado peso, como génesis de enfermedad, a condiciones de vida como la pobreza, la solvencia económica, la exclusión, la marginación y el racismo. Es decir, que en este plano es donde se incorporan y se aceptan, entre otros, los criterios y la ideología biomédica.

Así, la salud dependerá de la armonía que se establezca enlacontinuidad planteada, cimentada en el cumplimiento del mandato primordial de adorar, nutrir y sostener a las deidades $y$, en función de la pobreza o solvencia económica del núcleo familiar, en llevar correctamente las prácticas de cuidado y respeto del cuerpo, la familia y la sociedad, evitando al máximo las confrontaciones y la envidia. La enfermedad surge cuando la armonía se ve alterada en alguno de los planos o en ambos, y cualquier padecimiento se sitúa, según la gravedad o cronicidad, en cualquier parte del espectro, incluso alternadamente, predominando el polo que la subjetividad del sujeto privilegie. Por lo mismo, a esto se ligará la atribución de la causa de la enfermedad del "azúcar".

\section{Representaciones sobre la causalidad de la enfermedad del "azúcar" (diabetes mellitus)}

En Tenejapa hemos documentado que quienes padecen diabetes mellitus fundamentalmente sitúan 
la representación de la causa del padecimiento en el plano "natural", la atribuyen en primer término a malos hábitos de vida, y consideran como desencadenantes situaciones emocionales extremas o de larga duración.

En el otro polo nos encontramos con sujetos que consideran el susto como causa desencadenante, aunque no directa, o bien que la enfermedad les fue introducida por otra persona - por envidia u odio-. Sin embargo, la idea más frecuente en este polo es que les han echado mal (ak'chamel), lo que implica contratar a un $j$-ak'chamel (el que pone enfermedad), o bien a un "espiritista”, el cual, a través del espíritu que lo posee, recibirá las indicaciones para generar el daño.

De los dieciséis participantes, ocho se inclinaron, después de acudir con el pik'abal o el majtanil (el que puede ver/escuchar la sangre), por situar el origen de la diabetes mellitus en el ámbito estrictamente material y biológico, y descartaron que el "azúcar" provenga de que la deidad celestial abandone a sus hijos por no cumplir con el mandato primordial, o que "la mano del diablo esté ahí metida", es decir, que sea resultado de mal echado. De estos, como ya se señaló, se presentaron cuatro casos que consideramos representativos. Al respecto, de cada caso se hará un breve comentario, al margen de las conclusiones finales.

\section{Rafael}

Murió en 2011 a los 67 años debido a complicaciones de la diabetes, hecho que tuvo lugar un año después de realizada la entrevista. Padeció de "azúcar" durante quince años. Fue originario del paraje Cañada Chica y vecino de la cabecera municipal de Tenejapa. Era casado, tradicionalista y cursó la primaria completa. Además de ser pik'abal (el que puede ver y oír), ocupó un puesto destacado en la jerarquía religiosa tradicional como na’il, que significa, según él señaló, "jefe de todos los alférez". Trabajó durante veintiún años como vigilante en la escuela secundaria de Tenejapa, puesto del que se jubiló en octubre de 2006 con una pensión mensual de tres mil pesos. Contaba con Seguro Popular, al que acudía excepcionalmente y por problemas diferentes a la diabetes, y con servicio médico del ISSSTE ${ }^{7}$ sin embargo, no acudía a ninguna de las dos instituciones para el control de la diabetes.

Respecto a la subjetividad relacionada con el "azúcar", señaló que nunca buscó que le rezaran ni lo hizo para sí mismo:

Sí, pero es que sabemos que esa enfermedad no es para rezar. Porque también sé cuándo se puede rezar, pero es para otra enfermedad; pero ese azúcar, aunque reces. Es que nosotros sabemos [...] qué puede sanar un pik'abal. A veces soñamos que tal cosa, que te pegaron, que te caíste. Entonces sabemos que hay que rezar porque a nuestro ch'ulel lo molestan, pero eso llega a nuestro cuerpo, por eso sabemos bien cuándo se necesita pik'abal. Pero hay cosas que no necesitan pik'abal. Ahorita bien, sabemos que ese azúcar no lo necesita. Lo que necesito yo, lo que pienso yo, debe tener medicina, no más que no sabemos de qué medicina. Porque ese azúcar bien siento que está dentro de la sangre, no afuera, sino adentro de la sangre.

En su subjetividad, don Rafael adujo que su "azúcar" tuvo como causa directa la ingestión abusiva de cerveza, alimentos enlatados, botanas y refrescos y, aunque consideraba que comía bien, al inicio de la enfermedad perdió peso rápidamente. La insuficiencia renal fue la complicación que lo llevó a la muerte.

Don Rafael, que murió antes de cumplir los setenta años, alcanzó una posición socioeconómica que le permitió acceder a condiciones de vida por encima del promediode sus contemporáneos. El haber completadola primaria y su desempeño laboral en elámbito burocrático escolar, de alguna manera lo situaron en el entremedio del tradicionalismo y las representaciones dominantes sobre el mundo. Ello le permitió configurar una subjetividad desde la que distinguía con claridad lo perteneciente a cada ámbito. Pudo desarrollar plenamente su función sacerdotal tradicional, transitar y encabezar a lo largo de su vida la organización de la religiosidad tradicional, así como sancionar lo perteneciente a los campos de lo natural y lo sobrenatural. 
En su subjetividad claramente ubicaba la causa de su enfermedad en el ámbito material y situaba en el tiempo la época en que la diabetes empezó a presentarse en Tenejapa. Específicamente señaló los elementos mercantiles que la generaron y que empeoraron el panorama epidemiológico en su municipio.

\section{Cipriano}

Falleció en 2012 a los 59 años por insuficiencia renal. Padeció de "azúcar" durante siete años. Era originario de Cañada Chica y vecino de la cabecera municipal de Tenejapa. Era casado, tradicionalista, campesino y había estudiado un año de primaria. Fungió repetidamente como autoridad tradicional, era propietario de su casa en el centro de la cabecera, y sus hijos, entre los que se encontraban varios profesores, lo sostenían. Vivía acompañado de su esposa, una hija adolescente estudiante de bachillerato y, de manera temporal, una nuera con dos de sus hijos, a quien el esposo destinó para que cuidara del enfermo.

Antes de que lo atendiera el biomédico, su esposa lo llevó con rezadores, quienes invariablemente diagnosticaron "mal echado". Como no mejoraba y seguía enflaqueciendo, sus hijos lo llevaron a San Cristóbal de Las Casas, donde fue hospitalizado y diagnosticado con diabetes insulinodependiente.

$\mathrm{Al}$ año de iniciado el tratamiento dejó de aplicarse la insulina, debido a que insistentemente sus amigos le decían que ésta producía ceguera, e incluso consideraba que por aplicársela perdió la vista.

Durante el tiempo en que se le visitó, permaneció en cama debido al desaliento que le causó la ceguera, consecuencia de la persistente hiperglucemia que durante años sufrió.

Adujo como causa de su padecimiento el consumo desmedido de cerveza y señaló que, antes de la aparición de los síntomas, entre él y otro compañero se bebían en un día el equivalente a ochocientos pesos de dicha bebida. Consideraba que la diabetes insulinodependiente que padeció fue exclusivamente producto de malos hábitos y que no tenía que ver con aspectos religiosos o sobrenaturales. ${ }^{8}$ Debido a su ceguera, en abril de 2010 dejó de caminar y se postró, negándose a realizar actividad alguna. A principios del mes de febrero de 2011, don Cipriano murió. Entre sus comentarios finales destaca que nunca estuvo dispuesto a dejar la cerveza, aunque durante el tiempo en que le acompañé siempre negó que la ingiriera.

Podemos decir de don Cipriano que sus condiciones de vida estaban por encima de la línea de la pobreza; incluso contó en su momento con recursos suficientes para comprar y habitar una casa a unos pasos del cabildo de Tenejapa y para apoyar la formación de varios de sus hijos como maestros.

La inclinación cultural de don Cipriano al inicio de su enfermedad fue tratar de recuperar la salud con la ayuda de los pik'abaletik (quienes pueden ver y escuchar la sangre), a quienes inicialmente consultó, pero el fracaso de dichas terapias y la interacción intersubjetiva y subordinada con sus hijos - en los que ya predominaba una visión transubjetiva occidental- lo llevaron a optar, durante la mayor parte de su enfermedad, por una biomedicina matizada por las representaciones con prejuicios, presentes entre sus hijos y algunos médicos, respecto del uso de la insulina como "generadora de ceguera”. Estas creencias le condujeron a un uso errático de la misma, lo que, además de a la ceguera, llevó a don Cipriano a morir por insuficiencia renal.

Por otro lado, la inclinación tradicionalista de don Cipriano, la ceguera y las adicciones que durante su gestión religiosa adquirió, le llevaron a tomar la decisión de no sacrificar sus apetitos en aras de una vida que no quería seguir viviendo. Tanto fue así que, una vez que perdió la visión, decidió esperar la muerte en cama, se negó a recibir la insulina, y consumió refrescos sin límite y alcohol hasta la embriaguez, así como bebidas frutales de alto contenido calórico, a sabiendas de que todo eso apresuraría su deceso.

\section{Raúl}

Cuando se tuvo el primer contacto con don Raúl tenía 36 años, y al momento de la redacción de este trabajo tenía 40. Es originario del paraje San Antonio y vecino de la cabecera municipal de Tenejapa. Estudió la primaria completa, por 
lo que sabe leer y escribir y conoce matemáticas simples. Casado y bautista de religión, se desempeñaba en puestos diversos como empleado de mostrador, además de ser propietario de un pequeño tendejón.

Adujo que la causa directa de su padecimiento fue el consumo desmedido de cerveza:

Tomaba yo mucho porque ahí, en ese trabajo [Caminos y Puentes Federales], pues estamos en plebe, pues. Con los compañeros era la perdición allí, pues porque te llevaban allá: "Que vamos a echar unas copitas". Y ya empieza uno, pues. A veces a gastar el dinero antes de recibirlo, porque quincenal nos pagaban, pero quincenal teníamos que pagar también. Tomaba yo, a veces, dos o tres días en la semana.

Si bien pensaba que la ingestión de alcohol y una alimentación no sana fueron cimentando su enfermedad, consideraba que lo que desencadenó la diabetes fue que su tractor se desbarrancó:

Ese tractor iba a aplanar una casita, pué, que quería aplanar. Pero como la carretera estaba así [inclinada], pero ya después no subió, patinó, ya se fue resbalando el tractor. Tuve miedo, pué. Yo pensé que se había matado el operador. Como se fue, pué, se fue en el barranco. Ahí es donde, ora sí, que se me oscureció la mente, no supe cómo, sólo lo vi que se fue, ya no supe, me senté y ya al rato volví, como que volví otra vez, ya cuando voy viendo que hasta abajo estaba el tractor. Y allí empezó [el "azúcar"], parece.

Ante la incapacidad para realizar trabajo físico en el campo o la construcción, gracias a que sabía leer y conocía matemáticas simples había logrado consolidarse como empleado ejerciendo diversos puestos temporales tanto en instituciones federales, como en empresas de la localidad. Eso, aunado al tendejón que tenía en su casa, lo situó en una posición económica desahogada dentro de los estándares de pobreza de la localidad.

En su subjetividad, claramente ubicaba el origen de la diabetes en el ámbito material y biológico, y centraba el origen en el consumo excesivo de bebidas alcohólicas, principalmente cerveza, además de refrescos y grasas, lo cual, según refirió, fue cimentando la enfermedad. Sin embargo, situaba como desencadenante un susto, porque consideraba que los síntomas y signos de su "azúcar" se presentaron inmediatamente después del evento que le produjo el gran susto.

\section{Federico}

Tenía 42 años cuando se le entrevistó. Había estudiado primaria completa y era carpintero de oficio. Abandonó el tradicionalismo para convertirse al cristianismo y habitaba en el paraje Tsajalch'en. Consideraba que su padecimiento inició en diciembre de 2002 después de comer un pollo rostizado con abundante Coca-Cola en el parque recreativo conocido como Arcotete. Le empezó a dar mucha sed, que satisfacía con dicha bebida. Así pasaron siete días en los que no presentó poliuria, pero bajó rápidamente de peso.

Sospechó que tenía azúcar, por lo que acudió a la clínica. Consideraba que la diabetes no es contagiosa, como la tosferina, y que llega por tomar Coca-Cola.

Por ejemplo, los señores que llegan en los templos los días de fiesta. Es que yo vi una vez aquí en el templo Mesías, pero pura Coca, pura Coca. Si vas a un culto en otro templo, te dan de comer y tu Coca; y vas a otra iglesia u otro templo, otra Coca, y aparte te dan de comer pura carne. De hecho la carne no hace daño, sólo la Coca, sólo la Coca. Eso también me dijeron los doctores donde fui, me dijeron que ya no tomara Coca.

Debido a lo que consideró un fracaso de las pastillas que le recetaron en la clínica, a instancias de un hermano, y a pesar de su religión, acudió con un espiritista en San Cristóbal de Las Casas.

Entonces me revisó, pero él me dijo otra cosa, que no era azúcar lo que yo tengo. Eso fue lo que me dijo. Entonces le pregunté lo que tenía y me dijo que me había espantado, y yo le dije que era cierto. “Ah, pero sí 
lo sabes que fueron dos o tres veces que te espantaste; es que el azúcar nos da por susto; así como te pasó, ya se está convirtiendo en azúcar y es necesario que te revise y te cure". Fue lo que me dijo. "Está bien". Le dije. Sí, fue de eso y un poco de las envidias.

De la misma manera que en los casos anteriores, debido a su postura religiosa cristiana, en su subjetividad inicialmente situaba la diabetes en el ámbito biomédico y, como causa directa de su "azúcar", principalmente por el consumo de refresco. Consideraba que también este consumo tenía repercusiones en sus congéneres por la intensidad de su distribución. Sin embargo, el nulo efecto de los fármacos para el control de su enfermedad lo llevó a recurrir a un "espiritista”, con quien coincidió en la causa. Sin embargo, quitó importancia a lo que inicialmente propuso, y a partir de ese evento aseguró que su problema derivó de un susto. Finalmente, en ese deambular subjetivo que permite el horizonte conceptual, retomó los fármacos, con lo cual finalmente logró controlarse.

\section{Xiel (susto), pix'o'tan (envidia) y ak'chamel (mal echado)}

Los ocho restantes participantes de Tenejapa en algún momento consideraron que alguien les había hecho o echado ak'chamel (mal echado), aunque finalmente seis de ellos rechazaron dicho criterio para asumir el manejo del "azúcar" con fármacos o plantas medicinales.

Las otras dos personas, aun cuando han utilizado cualquier recurso al alcance de sus posibilidades económicas y de gestión, viven con la certeza de que el ak'chamel (mal echado), si bien no es el origen de su mal, es lo que lo hace persistir. Cabe señalar que la mayoría de pik'abaletikque han sido consultados por las personas entrevistadas han considerado que, en casi todos los casos, la enfermedad del "azúcar" no es de rezo.

\section{Micaela}

Originaria de Yaxanal, Tenejapa, Micaela tiene 51 años. No está inscrita en el Seguro Popular, es zapatista, analfabeta y habla con dificultad el español, por lo que fue necesario acudir a un traductor. Radica en la cabecera municipal, en un predio de su propiedad en el que vive desde pequeña. En lo que toca a religión, transita entre diferentes Iglesias, aunque se inclina predominantemente hacia el tradicionalismo.

¿Eh, católica? Ya no estamos en católica, sino que es que nos dijo un sobrino que el día sábado que es el mero que podemos descansar. Dice que lo buscaron ya en la Biblia, sí, por eso que ahí estamos yendo.

Se dedica al comercio. En su casa, que da a la calle, tiene una tienda donde vende algunas cositas, principalmente tamales que ella misma elabora. Los jueves instala un puesto en el mercado semanal de Tenejapa en el que vende fruta, verdura, tamales y textiles; además, renta varios cuartos que tiene en su predio. Afirma que anteriormente el negocio estaba mejor surtido pero que, por causa de los gastos que realizó por la enfermedad de su hija de 28 años, se fueron descapitalizando hasta quedar, según señala, muy pobres.

Calculaba que hacia 1997 comenzó su "azúcar” y que tres años después se puso grave y buscó atención en la clínica de Esquipulas en San Cristóbal de Las Casas. No sabía qué le habían dado, sólo que le recetaron inyecciones porque también le estaba fallando la vista.

En relación con las causas que dieron origen a su enfermedad, por momentos la atribuyó a la perenne tristeza que le causaron los decesos de su madre, su padre y su primer esposo, aunado a que, a la muerte de éstos, un medio hermano de ella, hijo de su padre, la despojó de su casa y terreno en su comunidad de origen. Consideraba como otra causa que su hija enfermó gravemente de vómito, evento durante el cual se le presentaron los primeros síntomas. A ello sumaba que había estado sometida durante años a fuertes golpizas por parte de su segundo esposo. Sin embargo, en la misma medida, y en otros momentos, aseguró que su enfermedad era resultado del ak'chamel (mal echado).

Los poxtawanejetik (los que ayudan a sanar) a los que recurrió le aseguraron que no había sanado debido a 
que su esposo estaba poniéndoles maldad a ella y a su hija porque quería que se murieran y así quedarse con el terreno y la casa. Al respecto, su hija señaló:

Todavía tiene cuatro semanas que mi mamá soñó que estoy en el hospital: "Si no me obedeces, se va a morir tu hija”, fue que le dijeron a mi mamá, pero en el cancuquero [pik'abal de Cancuc]. "Ya te he dicho varias veces, mándalo a curar, porque tú lo sabes bien. Tu esposo hay veces sale a las ocho de la noche y se va, sale a las diez". El cancuquero trajo unas velitas, pero así de tamañito que trajo, y así, al momento que trajo esas velitas, mi mamá le dijo: "Déjame verlo". Pero dice mi mamá que no lo pudo ver. "Míralo usted su trabajo del señor", que le dijo el cancuquero, "es el mismo señor que le está haciendo daño a tu hija. Tú lo sabes que está tu hija aquí en el hospital y no está contigo". Que le dijo el cancuquero, sí. No conocemos quién será el cancuquero que soñó mi mamá. Nada más lo soñó que es un cancuquero que le vino a decir que no está bien, que la enfermedad es por maldad. Pues sí, pero idónde vamos a conseguirlo, pues? A mi mamá le están diciendo, pero por el dinero no podemos hacer nada.

Un hito que marca la proclividad de Micaela a acceder a cualquier tratamiento que se le proponga es que durante un tiempo, animosamente, a pesar del alto costo, consumió productos de Herbalife y, en otro momento, plantas medicinales que le habían recomendado sus conocidos, además de tomar medicamentos en todo momento.

A pesar de contar con recursos económicos provenientes de diferentes fuentes y ser dueña de su casa, el tono de su narrativa remarcó siempre la pobreza e insuficientes recursos económicos para sobrellevar la vida cotidiana. En relación con su padecimiento, en su subjetividad más profunda se inclinó a atribuirlo a ak'chamel, y además fincaba su causa directa en circunstancias puramente emocionales, específicamente en la tristeza, la cual explicitó en varías de las visitas que le hicimos, en las que estaba ebria y lloraba por su padre y madre muertos.

Por otro lado, aunque no se vislumbró en sus opiniones, la narrativa se enmarcó en el sufrimiento por la violencia doméstica constante, que inició desde la muerte de sus padres y que perduraba hasta el día de la entrevista.

Dado que Micaela atribuía la persistencia del padecimiento a ak'chamel, no tomaba en cuenta el efecto que podían tener los alimentos chatarra en el control de su glucemia. Y, aunque lo negó, pudimos corroborar de primera mano una continua ingestión de refresco y que en ocasiones se mantenía ebria durante varios días.

Llama la atención en este caso la disponibilidad de Micaela a tomar para su padecimiento cualquier cosa que se le ofreciera. La vimos utilizar diferentes propuestas de fármacos, plantas medicinales y compuestos de Herbalife, así como acudir con diversos pik'abaletik, esto último con objeto de ser definitivamente curada.

\section{Enedina}

De habla tseltal, monolingüe y analfabeta, de aproximadamente 63 años de edad, Enedina no asistió a la escuela porque su padre pensaba "que los profesores se la iban a comer". De usos y costumbres tradicionales, en el predio en el que vivía se encontraban, a un lado de la suya, las viviendas de varios de sus familiares. Uno de sus hijos era maestro, otro político, y los demás se dedicaban a la agricultura o a la albañilería. No recibía ningún tipo de ayuda de ellos y se sostenía de los recursos que le proporcionaba el programa Oportunidades.

Su alimentación se limitaba a tortillas, pozol, frijol y verduras, y en algunas ocasiones carne. Tomaba CocaCola cada ocho días, o "cuando su corazón le pedía". Acompañaba las comidas con café azucarado o té. También, cuando "su corazón pedía", se embriagaba con pox (aguardiente), lo que sucedía con relativa frecuencia.

A Enedina, el pik'abal (el que puede ver y escuchar) le dijo que tenía envidia causada por la exmujer de su actual esposo, y tristeza por la muerte de uno de sus hijos. 
Debido a que Enedina no contaba con el apoyo material de sus hijos para realizar el gasto que implica consultar al pik'abal, sabía que no se curaría.

Refirió que, desde joven, su vida estuvo plagada de disgustos, además de que se embriagaba junto con su esposo con frecuencia y en dicho estado reñían en exceso. Otro hecho que marcó el sufrimiento en su vida fue que, en una ocasión, durante un rezo, recibió un balazo que uno de sus hijos pretendía dirigir a otra persona. A su esposo "no se le salió el cólico" y consideraba que eventualmente eso fue lo que quince días después lo llevó a la muerte, dejándola sola y triste.

Enedina, más que Micaela, mujer del caso anterior, era monolingüe, analfabeta y su vida ha transcurrido en un medio suburbano. Detentaba una subjetividad tradicionalista. Todo su padecimiento lo atribuyó a un proceso de largo plazo de ak'chamel que a la postre la llevó a sufrir de "azúcar" y a que el problema persistiera. Aunque estaba dispuesta a tomar medicamento y plantas, su subjetividad se reforzó debido a que ninguna medicina surtía efecto en su glucemia. Aseguraba que se curaría si sus hijos le proporcionaran el dinero para solventar los gastos de un pik'abal.

En cuanto a lo emocional, su trayectoria estaba marcada por violencia doméstica permanente, la cual ha coadyuvado a su empeoramiento. Destaca el hecho de que había recibido un balazo por parte de uno de sus hijos y la inmediata muerte de su marido.

Por otro lado, al igual que Micaela, Enedina no dio validez al hecho de que ciertos alimentos y bebidas coadyuvan al agravamiento y aparición de complicaciones, por lo que con frecuencia ingería CocaCola y se embriagaba con pox.

\section{Consideraciones finales}

Partiendo de la subjetividad que algunos diabéticos tseltales de la cabecera municipal de Tenejapa tienen sobre "padecer de azúcar", vislumbramos que quienes han tenido mayor interacción con agentes de la sociedad mestiza se inclinan a descartar los aspectos no naturales debido a una subjetividad retroalimentada desde la intersubjetividad social. Sitúan la enfermedad del "azúcar" en el ámbito natural, enunciando con claridad las causas directas y desencadenantes de su padecer, sin necesariamente descartar los diferentes factores presentes en el abanico conceptual que abarcan dicho ámbito y el sobrenatural. Además, los posibles derroteros a que se recurre para el manejo y control del padecimiento son coherentes con dicha subjetividad.

Respecto a las causas directas, principalmente consideran que su padecimiento se debe al uso y abuso de bebidas carbonatadas, entre las que destaca la CocaCola (Page, 2013), y al consumo de otros productos como la cerveza, las botanas fritas o "Sabritas" y productos enlatados. Aunque se preguntó, nadie hizo mención del factor hereditario, sino que reafirmaron como causa directa los malos hábitos alimenticios a nivel familiar.

Asimismo, enestegrupoparticular,independientemente de que lograran el control de la glicemia, las personas entrevistadas sabían que la diabetes mellitus es una enfermedad incurable que requiere de control y de medicamentos durante toda la vida y que, entre otras cosas, supone un importante riesgo de muerte temprana. Sabían que proviene de una mala alimentación, así como de la exposición a situaciones que alteran las emociones de manera crónica o aguda.

En lo que concierne a las dos mujeres, que aseguraron que la persistencia de su "azúcar" era resultado de ak'chamel (mal echado), ellas provenían de familias tradicionalistas —en situación de pobreza, analfabetas, monolingües, sujetas de violencia doméstica a lo largo de su vida y sin apoyo familiary sin recursos para recurrir al tipo de terapia a la que aspiraban, ya que consideraban que el "azúcar" era algo transitorio en sus vidas y que se curarían si encontraban a un pik'abal (el que puede ver y oír la sangre) con suficiente poder como para erradicar el daño que les habían impuesto.

Se caracterizaban por no dar importancia a las recomendaciones dietéticas, aun cuando estaban dispuestas a medicarse o a incorporar cualquier remedio que desde sus redes sociales se les sugiriera. Por otro lado, al igual que los que se inclinaban por la causalidad natural, fincaban una carga considerable para su mejoría en aspectos de orden emocional. Curiosamente, en este 
subgrupo nadie hizo referencia al susto o a la envidia como causas directas o indirectas de la enfermedad, sino exclusivamente al trabajo realizado por el j-ak'chamel (el que pone enfermedad), que fue contratado con el propósito de destruir a la enferma.

\section{Notas}

${ }^{1}$ El censo del 2000 reportó que el 92.27\% hablaba lengua indígena (INAFED, 2012).

2 Símil de brujería, mas no lo mismo, por poseer características propias que los distinguen de las prácticas mestizasy popularesmexicanas, sobre todoporlasformas de interceder valiéndose del $j$-ak'chamel (literalmente el que pone enfermedad) tenejapaneco, ante la entidad lab, mediante la capacidad de éste de transformarse en diferentes animales o fenómenos naturales, y que es de naturaleza gaseiforme, lo que le da capacidad de penetrar en los cuerpos de sus víctimas para dañarlos (Page, 2008 y 2010; Sánchez, 2013).

${ }^{3} \mathrm{El}$ susto produce la pérdida del ch'ulel (alma), que al ser liberado del cuerpo, lo expone a muy diferentes perjuicios causados por las deidades del mal y por demonios menores que habitan sobre la superficie de la tierra, entre otros, la enfermedad del "azúcar".

${ }^{4}$ Los sentimientos de envidia que influyen en el diabético son proyectados desde quien siente envidia hacia la víctima como emanaciones de excesivo calor o frío.

${ }^{5}$ Se entiende "transfiguración étnica" como el proceso a través del cual, como señalan Bartolomé y Barabas (1996: 28), se realizan "[...] sucesivas alteraciones internas tanto biológicas (mestizajes) como culturales, y en sus formas de relación con la sociedad envolvente" entre los grupos étnicos, en un intento por mantenerse como entidades étnicas ante el embate de los diferentes agentes de la sociedad dominante. Es decir, que la transfiguración supone la existencia de cambios adaptativos que cambian la fisonomía cultural."

${ }^{6}$ Merolico: curandero callejero.

7 ISSSTE: Instituto de Seguridad y Servicios Sociales de los Trabajadores del Estado.

${ }^{8} \mathrm{Si}$ bien desde la perspectiva biomédica se considera que la diabetes insulinodependiente está condicionada por factores genéticos, en la racionalidad del enfermo eso no prima, más bien su subjetividad al respecto refiere a una visión general sobre la enfermedad del "azúcar" y sus causas. ${ }^{9} \mathrm{El}$ sufijo etik implica el plural de la forma.

\section{Referencias bibliográficas}

Abric, Jean Claude (2004), Prácticas sociales y representaciones. México: Ediciones Coyoacán.

Biel, Joâo, Byron Good y Arthur Kleinman (2007a), "Introduction, Rethinking Subjectivity". En Joâo Biel, Byron Good y Arthur Kleinman (ed.), Subjectivity: Ethnographic Investigations. Berkeley: University of California Press.

Biel, Joâo, Byron Good y Arthur Kleinman (ed.) (2007b), Subjectivity: Ethnographic Investigations. Berkeley: University of California Press.

Bartolomé, Miguel A. y Alicia Barabas (1996), Lapluralidad en peligro. México: INAH-INI.

Consejo Nacional de Población (CONAPO) (2010), "Chiapas, región II Altos: grado de marginación por municipio". México: CONAPO. Disponible en: http:// www.conapo.gob.mx/work/models/CONAPO/ indices_margina/mf2010/AnexosMapas/Mapas/ Entidadesfederativas/MapasB7Chiapas/Mapa\%20 B72ChiapasRegion\%20II\%20Altos.jpg [consultado el 18 de noviembre de 2014].

Galinier, Jacques y Michel Perrin (1995), "Introducción”. En Jacques Galinier, Isabel Lagarriga y Michel Perrin (coords.), Chamanismo en Latinoamérica. Una revisión conceptual. México: Universidad Iberoamericana, Plaza y Valdés, Centro de Estudios Mexicanos y Centroamericanos.

Good, Byron J. (1994), Medicine, Rationality and Experience: an Anthropological Perspective. Nueva York: Cambridge University Press.

INEGI (2010), Información por entidad: Chiapas. México: INEGI. Disponible en: http://cuentame.inegi.org.mx/ monografias/informacion/chis/poblacion/default. aspx?tema=me\&ee $=07$ [consultado el 4 de diciembre de 2012].

Instituto Nacional para el Federalismo y el Desarrollo Municipal (INAFED) (2012), "Estado de Chiapas: 
Tenejapa”. En Enciclopedia de los municipios y delegaciones de México. México: INAFED. Disponible en: http://www. inafed.gob.mx/work/enciclopedia/EMM07chiapas/ index.html [consultado el 6 de noviembre de 2012].

Jodelet, Denise (2008), “El movimiento de retorno al sujeto y el enfoque de las representaciones sociales". En Culturay Representaciones Sociales. UnEspacio parael Diálogo Transdisciplinario, vol. 3, núm. 5. Disponibleen: www.ojs. unam.mx/index.php/crs/article/download/16356/1556 [consultado el 4 de diciembre de 2012].

Kleinman, Arthur (1988), The Illness Narratives: Suffering, Healing and the Human Condition. Estados Unidos: Perseus Books Group.

Menéndez, Eduardo (1994), "La enfermedad y la curación. ¿Qué es medicina tradicional?”. En Alteridades, vol. 4, núm. 7, pp. 71-83.

Menéndez, Eduardo (2005), “Antropología social como práctica y como representación". En Alteridades, vol. 15, núm. 29, pp. 65-80.

Page Pliego, Jaime (2005), Elmandato de los dioses: medicina entrelos tzotziles de Chamula y Chenalhó, Chiapas. México: Programa de Investigaciones Multidisciplinarias sobre Mesoamérica y el Sureste-Instituto de Investigaciones Antropológicas de la Universidad Nacional Autónoma de México.

Page Pliego, Jaime (2006), Ayudando a salvar: biografía del j-ilol Antonio Vázquez Jiménez. México: Programa de Investigaciones Multidisciplinarias sobre Mesoamérica yel Sureste-Institutode Investigaciones Antropológicas de la Universidad Nacional Autónoma de México.
Page Pliego, Jaime (2008), "Vivir en el miedo. La noción de lab en Oxchuc, Chiapas". En Revista Pueblos y Fronteras Digital, núm. 4. Disponible en: http://www. pueblosyfronteras.unam.mx/a07n4/pdfs/n4_art08. pdf [consultado el 10 de enero de 2013].

Page Pliego, Jaime (2010), Yombil "Puesta su flor en el altar". Una mirada a la etnomedicina en Oxchuc, Chiapas a partir de los j-poxtawanejetik organizados. México: Programa de Investigaciones Multidisciplinarias sobre Mesoamérica y el Sureste-Instituto de Investigaciones Antropológicas de la Universidad Nacional Autónoma de México.

Page Pliego, Jaime (2013), "Refresqueras y diabetes entre los mayas de los Altos de Chiapas". En LiminaR. Estudios Sociales y Humanísticos, vol. XI, núm. 1, enero-junio, pp. 118-133. Disponible en: http://iminar.cesmeca.mx/ index.php/rl/article/viewFile/102/89 [consultado el 10 de enero de 2013].

Pitarch, Pedro (1996), Ch'ulel: Una etnografía de las almas tseltales. México: Fondo de Cultura Económica.

Sánchez Carrillo, Óscar (2013), Winiketik, ajch'alotik, antsetik, lumutik. Hombres de lodo, mujeres de tierra, elementos de configuración de la persona tseltal de Yajalón. Tesis de doctorado, Facultad de Filosofía y Letras, Instituto de Investigaciones Antropológicas de la UNAM, México.

Secretaría de Desarrollo Social (SEDESOL) (2012), Cédula de información municipal, Tenejapa, Chiapas. México: Gobierno Federal. 
Cuadro 1. Mortalidad por diabetes por sexo. Tenejapa, Chiapas. 2008 a 2011

\begin{tabular}{lrrrrrrrrr} 
Año & Mujeres & $\begin{array}{c}\text { Rango } \\
\text { de edad }\end{array}$ & $\begin{array}{c}\text { Promedio } \\
\text { de edad }\end{array}$ & Hombres & $\begin{array}{c}\text { Rango } \\
\text { de edad }\end{array}$ & $\begin{array}{c}\text { Promedio } \\
\text { de edad }\end{array}$ & $\begin{array}{c}\text { Total } \\
\text { Tasa por } \\
100 \text { ooo } \\
\text { habitantes }\end{array}$ & $\begin{array}{c}\text { Núm. de } \\
\text { causa de } \\
\text { muerte }\end{array}$ \\
\hline 2008 & 3 & $59-85$ & 73 & 1 & 39 & 39 & 4 & 10.18 & $6^{\text {a }}$ \\
2009 & 7 & $39-77$ & 63 & 4 & $42-53$ & 49 & 11 & 27.65 & $2^{\text {a }}$ \\
2010 & 10 & $13-59$ & 39.3 & 8 & $39-84$ & 59.1 & 18 & 44.7 & $1^{\text {a }}$ \\
2011 & 2 & $46-68$ & 52 & 7 & $30-80$ & 62.4 & 9 & 22.08 & $1^{\text {a }}$ \\
Total & 22 & & 53.54 & 20 & & 60.26 & & & \\
\hline
\end{tabular}

Fuente: elaboración propia a partir de datos de la investigación.

\section{Cuadro 2. Relación de casos de diabetes mellitus tipo II no insulinodependiente, participantes de Tenejapa para este trabajo}

\begin{tabular}{|c|c|c|c|c|c|c|c|c|c|}
\hline $\begin{array}{l}\text { Nombre } \\
\text { (ficticio) }\end{array}$ & $\begin{array}{l}\text { Edad al ser } \\
\text { entrevistado }\end{array}$ & Sexo & $\begin{array}{l}\text { Localidad } \\
\text { de } \\
\text { residencia }\end{array}$ & Religión & $\begin{array}{l}\text { Inicio } \\
\text { DM }\end{array}$ & $\begin{array}{l}\text { Tipo } \\
\text { DM }\end{array}$ & Escolaridad & $\begin{array}{l}\text { Causa } \\
\text { directa }\end{array}$ & $\begin{array}{c}\text { Causa } \\
\text { desencadenante }\end{array}$ \\
\hline Rafael & 66 & M & Tenejapa & Tradicional & 1995 & II & Primaria & $\begin{array}{r}\text { Ingesta } \\
\text { abusiva de } \\
\text { cerveza }\end{array}$ & No señala \\
\hline Cipriano & 58 & M & Tenejapa & Tradicional & 2005 & II & $\begin{array}{r}1^{\circ} \mathrm{de} \\
\text { primaria }\end{array}$ & $\begin{array}{r}\text { Ingesta } \\
\text { abusiva de } \\
\text { cerveza, } \\
\text { refresco y } \\
\text { botanas }\end{array}$ & No señala \\
\hline Raúl & 36 & M & Tenejapa & Bautista & 1994 & II & Primaria & $\begin{array}{r}\text { Ingesta } \\
\text { abusiva de } \\
\text { cerveza, } \\
\text { refresco y } \\
\text { botanas }\end{array}$ & Susto \\
\hline Federico & 42 & M & Tsajalch'en & Católico & 2002 & II & Primaria & $\begin{array}{r}\text { Ingesta } \\
\text { abusiva de } \\
\text { cerveza, } \\
\text { refresco y } \\
\text { botanas }\end{array}$ & No refiere \\
\hline Micaela & 49 & $\mathrm{~F}$ & Tenejapa & Tradicional & 2001 & II & Analfabeta & $\begin{array}{r}\text { Ak'chamel } \\
\text { (mal } \\
\text { echado) }\end{array}$ & $\begin{array}{r}\text { Violencia } \\
\text { doméstica, } \\
\text { susto }\end{array}$ \\
\hline Enedina & 63 & $\mathrm{~F}$ & Tenejapa & Tradicional & 2000 & II & Analfabeta & $\begin{array}{r}\text { Ak'chamel } \\
\text { (mal } \\
\text { echado) }\end{array}$ & $\begin{array}{r}\text { Violencia } \\
\text { doméstica, } \\
\text { susto }\end{array}$ \\
\hline
\end{tabular}

Diabetes mellitus tipo I = insulinodependiente.

Diabetes mellitus tipo II = controlable con dieta, ejercicio y medicamentos.

Fuente: elaboración propia 